\title{
Influence of Ultrasonic Surface Rolling Process and Shot Peening on Fretting Fatigue Performance of Ti- 6Al-4V
}

Ning Wang ( $\nabla$ nwang@ecust.edu.cn )

East China University of Science and Technology https://orcid.org/0000-0002-8382-9708

Jin long Zhu

East China University of Science and Technology

Bai Liu

East China University of Science and Technology

Xiancheng Zhang

East China University of Science and Technology

Jiamin Zhang

East China University of Science and Technology

Shantung Tu

East China University of Science and Technolgy

\section{Original Article}

Keywords: fretting fatigue, residual stress, ultrasonic surface rolling process, surface strengthening

Posted Date: January 6th, 2021

DOI: https://doi.org/10.21203/rs.3.rs-139253/v1

License: () (1) This work is licensed under a Creative Commons Attribution 4.0 International License.

Read Full License 


\section{Title page}

\section{Influence of Ultrasonic Surface Rolling Process and Shot Peening on Fretting Fatigue Performance of Ti-6Al-4V}

Ning Wang, born in 1980, is currently an Associate Professor at Key Laboratory of Pressurized System and Safety, East China University of Science and Technology, China. She received her PhD degree from East China University of Science and Technology, in 2013. Her research interests include structural integrity, metal corrosion, creep and fretting fatigue of components.

Tel: +86-21-64253513; E-mail: nwang@ecust.edu.cn

Jin-Long Zhu, born in 1995, is currently a master candidate at Key Laboratory of Pressurized System and Safety, East China University of Science and Technology, China.

E-mail:kric zhu@163.com

Bai Liu ,born in 1996, is currently a master candidate at Key Laboratory of Pressurized System and Safety, East China University of Science and Technology, China.

E-mail: 18351806103@163.com

Xian-cheng Zhang, born in 1979, is currently a professor at Key Laboratory of Pressurized System and Safety, East China University of Science and Technology, China. He received his $\mathrm{PhD}$ degree from Shanghai jiaotong Universtiy, China, in 2008. His main research interests include fatigue fracture theory of multi-component structures, the design method and theory of material safety tolerance under extreme environment.

Tel: +86-21-64253149; E-mail: xczhang@ecust.edu.cn

Jia-Min Zhang,born 1994, is currently a master candidate at Key Laboratory of Pressurized System and Safety, East China University of Science and Technology, China.

E-mail: 1152582012@qq.com

Shan-tung Tu, born in 1961, is currently an Academician of Chinese Academy of Engineering and a professor at Key Laboratory of Pressurized System and Safety, East China University of Science and Technology, China. His main research interests include chemical equipment safety, high temperature strength, advanced energy materials and equipment.

E-mail: sttu@ecust.edu.cn

\section{Corresponding author: Ning Wang E-mail: nwang@ecust.edu.cn}




\title{
Influence of Ultrasonic Surface Rolling Process and Shot Peening on Fretting Fatigue Performance of Ti-6Al-4V
}

\author{
Ning Wang* • Jin-Long Zhu •Bai Liu• Xian-Cheng Zhang• Jia-Min Zhang • Shan-Tung Tu \\ (Key Laboratory of Pressurized System and Safety, East China University of Science and Technology, Shanghai \\ 200237,China)
}

\begin{abstract}
The shot-peening (SP) and ultrasonic surface rolling process (USRP) were performed on Ti-6Al$4 \mathrm{~V}$ plate specimens. The surface hardness and residual stresses of the material were tested by vickers indenter and X-ray diffraction residual stress analyzer. The effects of different surface strengthening on its fretting fatigue properties were verified by fretting fatigue experiments. It is shown (i) that the fretting fatigue life of Ti-6Al-4V effectively improved after USRP and SP and (ii) that the surface integrity of specimens after USRP is the best, which has deeper residual compressive stress layer and more refined grain. The fretting fatigue fracture surface and wear morphology of the samples were studied and analyzed by means of microscopic observation, and the mechanism of improving fretting fatigue life by surface strengthening process was further explained
\end{abstract}

Keywords: fretting fatigue; residual stress; ultrasonic surface rolling process; surface strengthening

\section{Introduction}

Fretting fatigue refers to small relative displacements in regions of contact between two parts while the contacting parts are subjected to vibratory load, as shown in Fig. 1. Compared with uniaxial fatigue, fretting fatigue crack initiation mainly occurs at the geometric discontinuity of the contact zone, where the fretting damage is the most serious In addition, fretting will accelerate the wear, occlusal and material loss of the surfaces in contact, which greatly reduces the mechanical properties of the material. At the same time, it will accelerate the initiation and propagation of cracks and even early fracture of the specimen. A large number of engineering cases [1-2] show that fretting will greatly reduce the service time of components by $20 \%-50 \%$, or even more. Among them, the reports about fretting fatigue leading to premature fatigue failure of the joints of aero-engine blades are particularly prominent. [3-5].

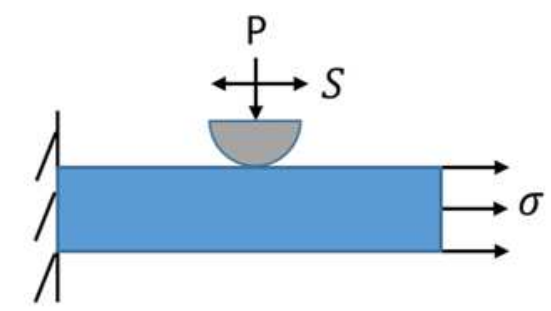

Fig. 1 Schematics of the fretting fatigue.
Titanium alloy is one of the materials that widely used in aerospace and other fields, which has a series of advantages such as high specific strength, stable high temperature performance, etc. However, due to the high friction coefficient and poor wear resistance of titanium alloy, it is particularly sensitive to fretting wear and crack initiation, which seriously affects the safety and service life of titanium alloy components. Therefore, it is necessary to adopt some surface strengthening methods to improve its fatigue and wear resistance. Surface strengthening refers to the process of changing the structure of the material surface by applying external force or heat treatment, so as to improve the surface strength, hardness, fatigue resistance, wear resistance, surface integrity. Some common surface strengthening processes in engineering mainly include wet shot-peening [6-7], laser shock [8-9], surface coating [1011], composite surface strengthening treatment [12-13], etc. A large number of studies have shown that surface strengthening improves the fatigue resistance of materials mainly due to the introduction of residual compressive stress. The improvement of wear resistance is mainly shown in the improvement of material surface and subsurface micro-hardness, smaller surface roughness, surface layer gradient nanostructures, etc. No matter what kind of surface strengthening process is used, the fundamental purpose is to avoid wear from appearing in the crack area of the fretting graph [14]. Li et al. [15] found that the improvement of surface strength after wet SP can effectively resist local fatigue caused by fretting. At the same time, the residual compressive stress can also effectively hinder the crack propagation. Liu et al. [16] found that USRP effectively improved the surface hardness of Inconel 690TT by refining the surface and subsurface grains. Plasma Nitriding (PN) improves the surface hardness by infiltrating nitrogen atoms into the surface of the material to change the chemical composition of the matrix. Through comparative analysis of USRP, USRP+PN and PN strengthening process, it is proved that USRP+PN makes Inconel 690TT have the best wear resistance and can effectively hinder the initiation and propagation of cracks. It is also found that the different surface treatments (substrate: BM, shot peening: SP, IBED CrN coating: $\mathrm{CN}$, CuNiIn coating: $\mathrm{Cu}$ ) on $\mathrm{Ti}-6 \mathrm{Al}-4 \mathrm{~V}$ alloy can effectively improve the fretting fatigue life[17]. Compared with USRP, mechanical surface polishing would weaken the fretting 
fatigue performance of Ti-6Al-4V [18]. In terms of improving fatigue strength, the residual compressive stress produced by USRP is better than the surface gradient nanostructures produced by mechanical surface polishing. The fatigue strength is increased by $113.6 \%$. The residual compressive stress is considered to be the key factor to improve the fretting fatigue life. $\mathrm{Lu}$ [19] pointed out that high hardness would block the initiation of cracks. The coupling effect of the residual compressive stress and the plastic deformation layer will slow down the early growth of fretting fatigue cracks and the residual compressive stress plays a major role.

Shot-peening (SP) is widely used in the aerospace field because of its mature technology, high processing efficiency, the ability to process the surface of various complex shapes, etc. While ultrasonic surface rolling process (USRP) is an emerging technology that superimposes static pressure and ultrasonic vibration impact force as a combined load applied to the contact surface of the ball and the component. Compared with traditional surface strengthening technologies, it can make the material surface produce a denser plastic deformation layer, higher surface roughness, better wear resistance and introduce a deeper residual compressive stress layer [20-21]. The schematic diagrams of the two processes are shown in Fig. 2(a)\&(b).

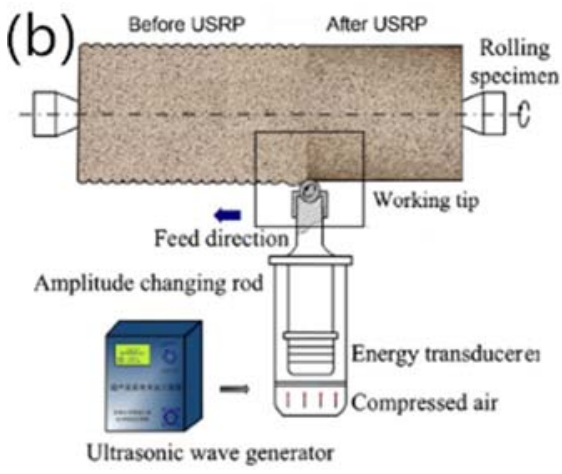

Fig. 2 Schematics of different surface strengthening processes: (a) SP [22] (b)USRP [23].

Based on the above research background, the surface of Ti-6Al-4V was strengthened by USRP and SP processes. The combined effects of residual compressive stress and surface roughness on fretting fatigue life of Ti-6Al-4V were studied, and the effect of strain on wear resistance of paper surface was studied.

\section{Experimental}

\subsection{Material and specimen}

The material used in the experiments is a duplex alloy (Ti-6Al-4V, Fig. 3), which is commonly used to make turbine blades of aeroengine. The heat treatment state are forging and annealing. The principal chemical composition of Ti-6Al-4V are given in Table 1. The main material properties at room temperature of Ti-6Al-4V are listed in Table 2.

Ti-6Al-4V alloy specimen was prepared by wire cutting, grinding and polishing. Fig. 4 shows the geometrical details of the fretting fatigue plate specimen.

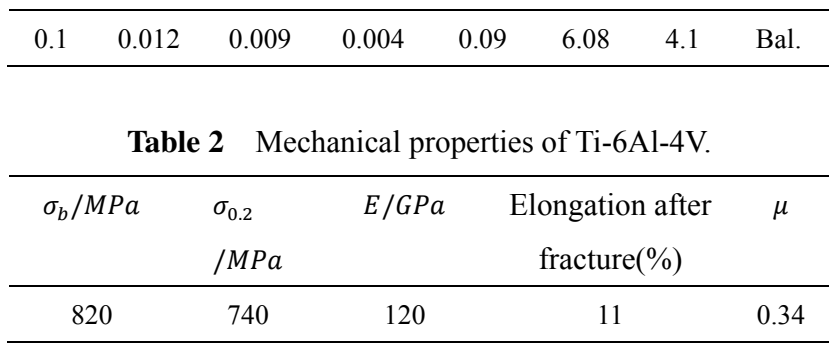

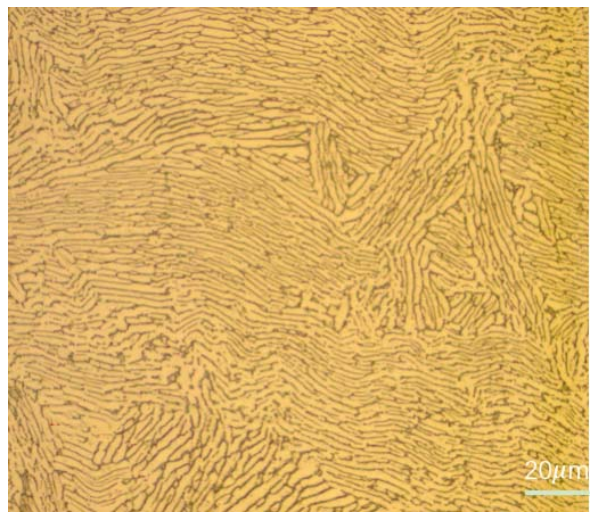

Fig. 3 The microstrcture image of specimen.

Table 1 Chemical composition of Ti-6Al-4V(wt\%).

\begin{tabular}{llllllll}
\hline $\mathrm{Fe}$ & $\mathrm{C}$ & $\mathrm{N}$ & $\mathrm{H}$ & $\mathrm{O}$ & $\mathrm{Al}$ & $\mathrm{V}$ & $\mathrm{Ti}$ \\
\hline
\end{tabular}




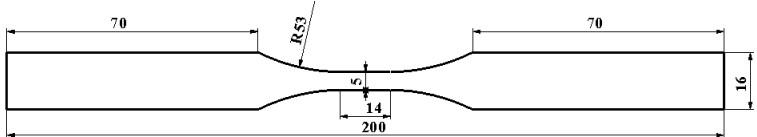

Fig. 4 Geometric details of the specimen. (units:mm).

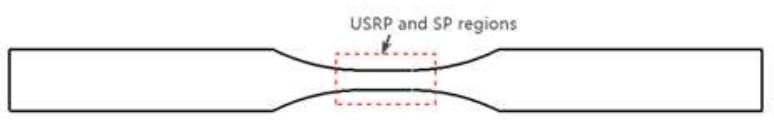

Figure 5 Schematics of USRP and SP treatment regions.

\subsection{Different surface strengthening processes}

In the process of USRP, static pressure processing parameter is $180 \mathrm{~N}$, amplitude of ultrasonic vibration is $20 \mu \mathrm{m}$, feed rate is $2000 \mathrm{~mm} / \mathrm{min}$, distance between each pass is $0.05 \mathrm{~mm}$, processing times are 20 . The small ball at the machining head is made of carbide with diameter of $10 \mathrm{~mm}$.

In the process of SP, material is $0.3 \mathrm{~mm}$ ceramic shot, coverage rate is $100 \%$, shot pressure is $1 \mathrm{bar}$, shot flow rate is $3 \mathrm{~kg} / \mathrm{min}$, shot distance is $150 \mathrm{~mm}$, shot time is $8 \mathrm{~s}$.

\subsection{Microhardness and residual stress}

The surface strengthened by SP and USRP is two parallel end faces in thickness direction and the arc surface at $1.5 \mathrm{~mm}$ radian, as shown in Fig. 5. It is aimed to prevent the specimen from breaking near the geometric discontinuity during the experiment.

The residual stress of specimen is measured by ProtoIXRD MG40P FS STD residual stress analyzer. The specimen is a cuboid with the size of $5 \times 5 \times 6 \mathrm{~mm}$. Cu target is selected in the test. The $\mathrm{X}$-ray generator tube voltage is $24 \mathrm{kV}$, tube current is $7 \mathrm{~mA}$, diameter of collimator is $1 \mathrm{~mm}$ and the exposure time is $5 s$. In order to accurately obtain the residual stress field along the depth direction after USRP, the residual stress is measured by electrolysis layer by layer. The ratio of perchloric acid to formaldehyde is 1:9. The polishing voltage is $15 \mathrm{~V}$. When measuring the residual stress, three different positions are tested in the horizontal direction of each depth so that the test error can be reduced by calculating the mean value.

\subsection{Surface roughness}

Microhardness is measured by HXD-1000MC/CD micro Vickers hardness tester. The load is $200 G F$ and the holding time is $15 \mathrm{~s}$. Five effective points were measured at the same depth and the average value was taken. The interval between each data point is $50 \mu \mathrm{m}$. The hardness value is measured every $50 \mu \mathrm{m}$ in depth direction. This method can obtain enough data and minimize the influence of hardness indentation on adjacent positions. Since the measurement of microhardness requires good surface roughness, metallographic specimens are directly used for hardness measurement.

The surface roughness of Ti-6Al-4V before and after SP and USRP process are measured by IFM G4 3D surface topography instrument. The mean deviation Ra of profile arithmetic is taken as the surface roughness characterization parameter.

\subsection{Fretting fatigue experiment}

Fretting fatigue experiment is completed by installing fretting wear device on INSTRON fatigue testing machine. The fatigue load provided by INSTRON fatigue testing machine is sinusoidal load. The experiment frequency is $10 \mathrm{~Hz}$ and the stress ratio is 0.1 . The single chuck fretting wear device designed is mainly used to provide stable and fixed normal load. The normal load is mainly applied by real-time digital display torque wrench. The four symmetrical screws on the stress ring are mainly connected with the bottom plate to ensure that the whole mechanism can be horizontally and stably fixed on the tray. The fixing bolts on both sides are used to fix and support the bolt rod and prevent excessive vibration of the bolt rod during the experiment, as shown in Fig. 6 and Fig. 7.

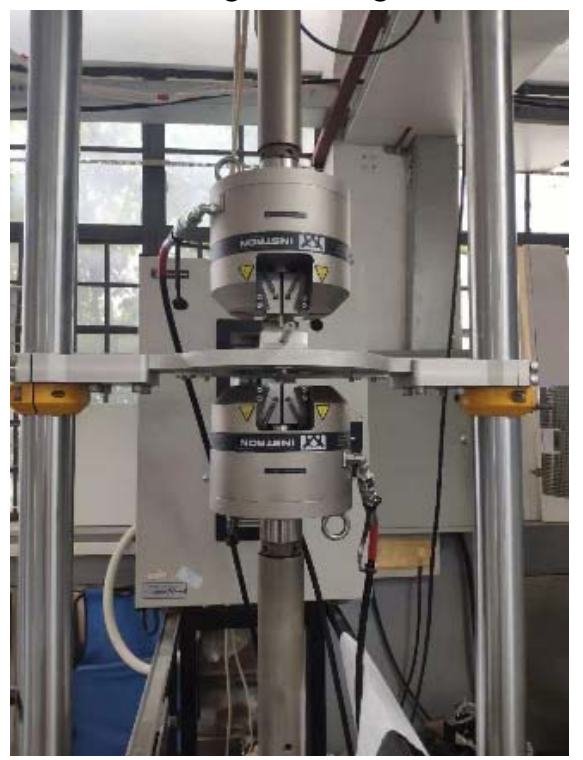

Fig. 6 The fretting fatigue experiment machine.

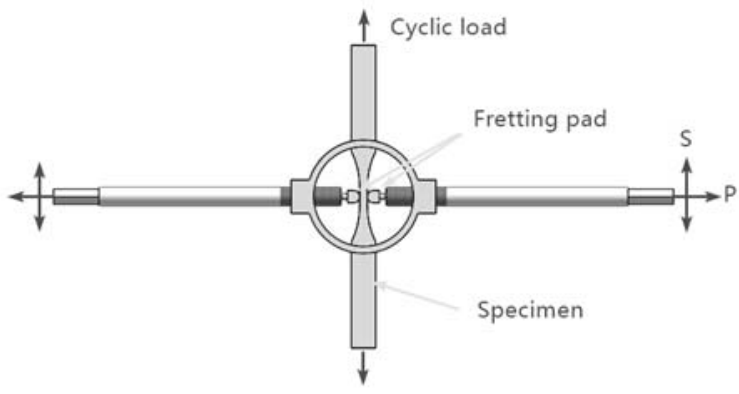

Fig. 7 Schematic of fretting wear arrangement. 
The experiment conditions are shown in Table 3. In order to achieve the purpose of comparison, fretting fatigue experiments are carried out on untreated specimens(As Received, AsR), SP and USRP specimens under each operating conditions. A total of 27 groups of experiments were carried out, and there were 3 samples in each condition..

Table 3 Fretting fatigue experiment conditions.

\begin{tabular}{ccc}
\hline Stress level & $\begin{array}{c}\text { Axial } \\
\text { load/MPa }\end{array}$ & $\begin{array}{c}\text { Normal } \\
\text { load/MPa }\end{array}$ \\
\hline AsR & 600 & \\
& 625 & Constant \\
& 650 & \\
USRP & 600 & Constant \\
& 625 & \\
& 650 & Constant \\
SP & 600 & \\
& 625 & 650 \\
\hline
\end{tabular}

\section{Results and discussion}

\subsection{Surface roughness, Microhardness and}

\section{residual stress}

The surface roughness distribution of different specimens are shown in Fig. 8. It can be seen that the surface roughness of Ti-6Al-4V is significantly improved after USRP. The surface roughness ( $\mathrm{Ra}$ ) of AsR specimen is $0.217 \mu \mathrm{m}$. After USRP, it reduces to $0.143 \mu \mathrm{m}$. However, compared with the AsR specimen, the surface roughness increases after SP, which is $1.279 \mu \mathrm{m}$.

It also can be seen from the figure that the surface asperities of the specimen under different surface treatments are not the same. For the AsR specimen, the highest point of the asperity reaches $0.9 \mu \mathrm{m}$. The distance between asperities on the left side of $1.5 \mathrm{~mm}$ is relatively close while on the right side is larger and the distance can be up to $0.3 \mathrm{~mm}$ in width. The two-dimensional contour map is small and sharp. The gap between two adjacent asperities is likely to be a potential microcrack. The larger the gap, the more likely it is to become a crack. However, the distance between the two asperities of the specimen after SP is relatively large and the maximum point can reach $0.4 \mathrm{~mm}$. Throughout the overall trend in Fig. 8(b), almost every two asperities have different sizes of spacing and even have obvious characteristics similar to pits. The two-dimensional contour map seems wide and high. The more the gap between the asperities, the wider the gap spacing, which means that the material is more likely to initiate microcracks on the surface and more likely to be damaged under the same working conditions. The height of the asperities of the USRP specimen are mostly about $0.4 \mu \mathrm{m}$ and the height tends to be horizontal. The asperities are relatively tightly connected and do not have obvious gap. The whole two-dimensional contour map is dense and sharp. By comparison, it can be seen that the number of asperities of specimen after SP has increased significantly, while it greatly reduced after USRP.

The microhardness distribution of different specimens are shown in Fig. 9. The microhardness of USRP and SP specimen are obviously greater than AsR specimen at the same depth. USRP specimen reaches the maximum value of $374 \mathrm{HV}$ at the depth of $150 \mu \mathrm{m}$. SP specimen reaches the maximum value of $368 \mathrm{HV}$ at the depth of $80 \mu \mathrm{m}$. It can also be seen from the figure that the microhardness of USRP specimen is greater than that of SP specimen. The microhardness of SP specimen is basically the same as the as received specimen at the depth of $450 \mu \mathrm{m}$, while the USRP specimen at the depth of $550 \mu \mathrm{m}$. Therefore, USRP has a deeper influence on the hardness of specimen than SP. The main reason for the increase in microhardness is grain refinement [24]. At the same time, because the microhardness distribution results of the specimens can objectively reflect the distribution trend of the plastic strain of the material [25], the plastic strain layer thickness of the specimen after USRP is also deeper.

The residual stress distribution of different specimens are shown in Fig. 10. The residual compressive stresses of specimens after USRP and SP are first increase and then decrease in the depth direction and all reach the maximum value on the subsurface. Wohlfahrt [26] used Hertz contact theory to explain this phenomenon. He believed that it was mainly caused by the competition mechanism between Hertzian dynamic pressure and surface plastic deformation. When the subsurface strain is dominant in the competition with surface plastic deformation, the maximum residual stress will be located in the subsurface layer. The residual stress of the specimen that strengthened by USRP reaches the maximum of $-550 \mathrm{MPa}$ at the depth of $0.18 \mathrm{~mm}$, while the SP-strengthened specimen reaches the maximum of $380 \mathrm{MPa}$ at the depth of $0.1 \mathrm{~mm}$. In addition, the influence range of residual compressive stress field after USRP is deeper than that of SP. The residual stress value is also larger at the same depth. The surface residual compressive stress of the AsR specimen is between $35 \mathrm{MPa}$ and $72 \mathrm{MPa}$ and the affected layer is very shallow, about $20 \mu \mathrm{m}$. Some scholars believed that a deeper residual compressive stress layer is beneficial to prolong the propagation life of cracks, because it can effectively delay the propagation rate of cracks. In addition, the higher residual compressive stress can well offset the external load on the surface,which has a positive effect on the resistance to crack initiation [27]. 
Therefore, USRP has a better effect than SP on the improvement of fretting fatigue life of Ti-6Al-4V.
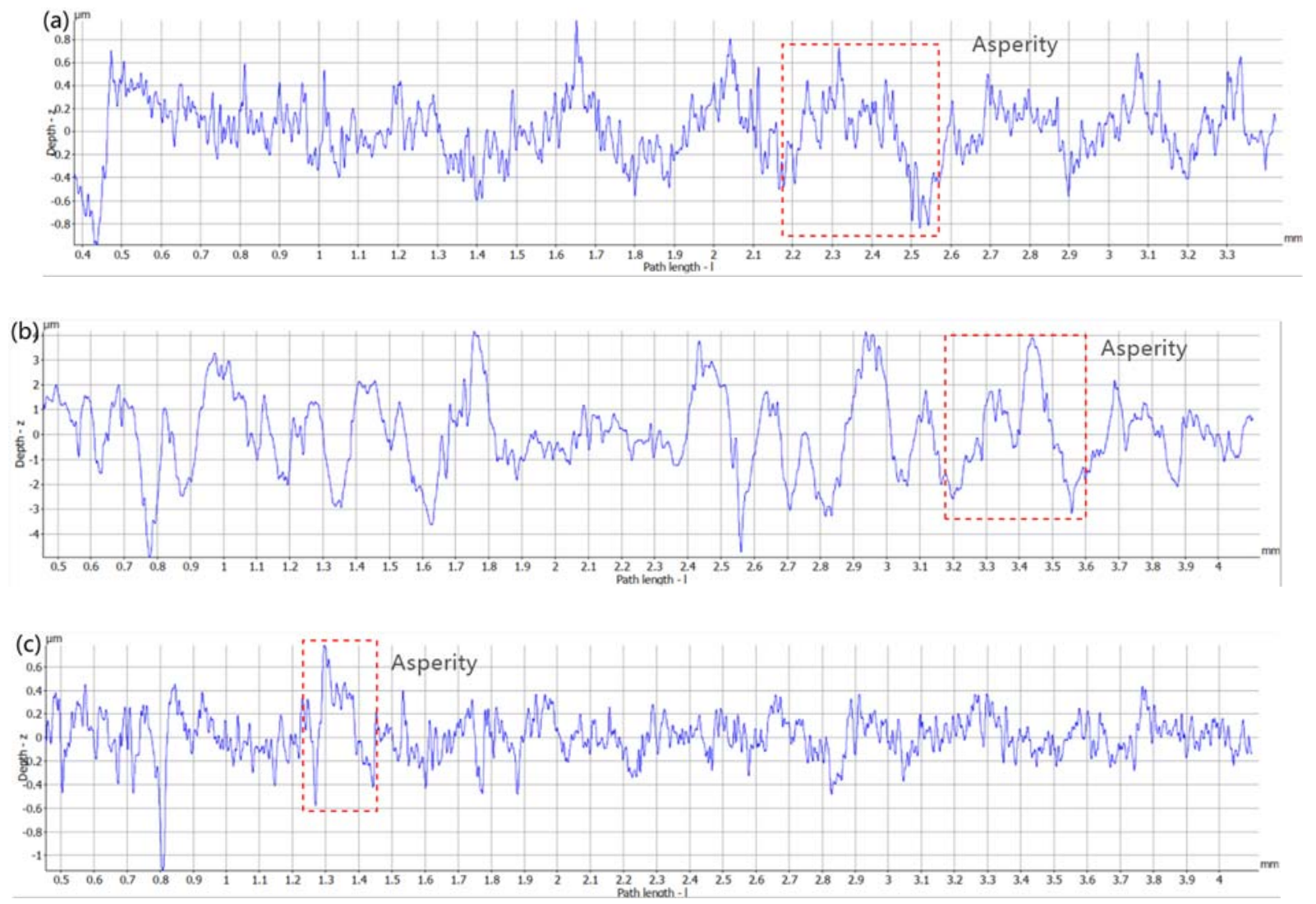

Fig. 8 The surface roughness of the (a)AsR,(b)SP and (c)USRP specimens

Fig. 9 The Microhardness distribution of the AsR,SP and USRP specimens

\subsection{Wear profile}

The morphology of fretting areas on the surface of specimens after fretting fatigue experiment are shown in Fig. 11. The locations of fracture failure are all located in
Fig. 10 Distribution of compressive residual stress of the SP and USRP specimens

the fretting area. Observing the fretting area, the specimen has a certain degree of elastic and plastic deformation. It can be seen from Fig. $11(\mathrm{a} \& \mathrm{~b})$ that there are large areas of slip marks in AsR specimens, mainly adhesion and a small 
amount of delamination. The SP specimen (Fig. 11 (c\&d)) has obvious flaking of massive material at the fracture position, which may be caused by the initial collection of microcracks under the combined action of axial fatigue load and contact stress. In the fretting area, there are slight wear marks, delamination and a few micro-cracks and the surface also appears embrittlement. This is probably because a large amount of shots bombard the surface of the specimen during the SP process, the surface grain of the specimen is refined but not uniform. In contrast, only slight delamination and smaller wear pits exist on the USRP specimen (Fig. 11 (e\&f)) . This is because the surface and sub-surface grains are refined and relatively uniform, the wear resistance is improved. In addition, no cracks can be found in the wear area and only a few wear pits exist. It is possible that the specimen is in a global slip state during the fretting process. Similar to the results of Mohd [28], cracks initiate at the boundary between the adhesion zone and the sliding zone in the local sliding zone, while only accumulated debris is found in the overall sliding zone.It means fretting wear is dominant in the competition mechanism with fatigue during the fretting process. The wear rate is greater than the crack initiation rate so that the initiating microcracks are worn away.

\subsection{Fracture analysis}

Through the fretting fatigue experiment, the crack initiation and fracture failure of all specimens are located on the side of the lower edge of the fretting contact area. The wear marks on the surface of the fretting contact area

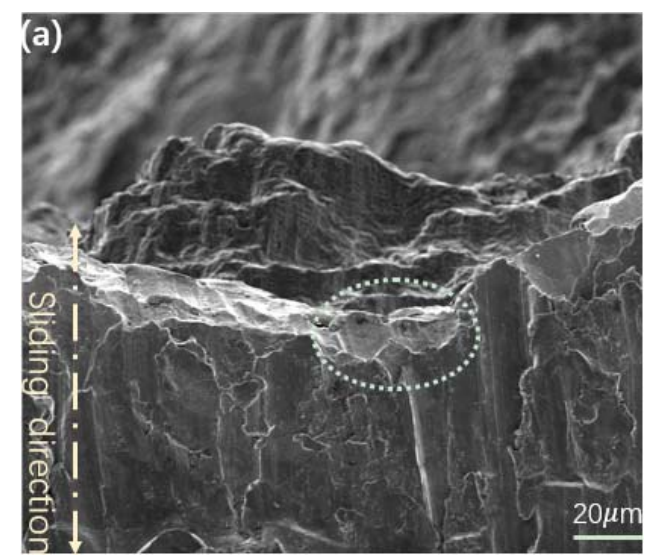

is a typical fretting fatigue failure. The macroscopic view of the fracture surface after fretting fatigue failure are shown in Fig. 12. The fatigue crack originates close to the contact surface of the specimen.Because the normal load is applied through the micro-motion pad and the contact form between the micro-motion pad and the specimen is "cylindrical-planar" contact. According to Hertz contact theory, there is serious stress concentration in the contact area. Thus, the main crack source must be formed in the contact area. Regardless of whether there are defects in the crack source area, fatigue cracks are initiated from the maximum stress concentration area because the initiation of cracks must undergo repeated slippage processes to form [29]. Moreover, the form of crack propagation is radial expansion with the main crack source as the center, similar to "ripple" diffusion. Eventually, the fracture failure occurred in the transient area. In addition, there are wear pits in the crack source area of the AsR (Fig. $12(a \& b)$ ) specimen. This is due to the low hardness and poor wear resistance, the titanium alloy is easy to be affected by fretting wear during the fretting process[30]. While after SP process, the surface hardness of the specimen is improved and the subsurface also has a certain degree of nanogradient structure, which can effectively resist fretting wear. However, due to the surface embrittlement and the increase of roughness, the wear resistance will be weakened to a certain extent. As a result, the traces of wear damage can be found in the crack source area. However, the surface hardness of the specimen after USRP is improved and the surface roughness is greatly reduced. Therefore, the specimen after USRP can better resist fretting damage.

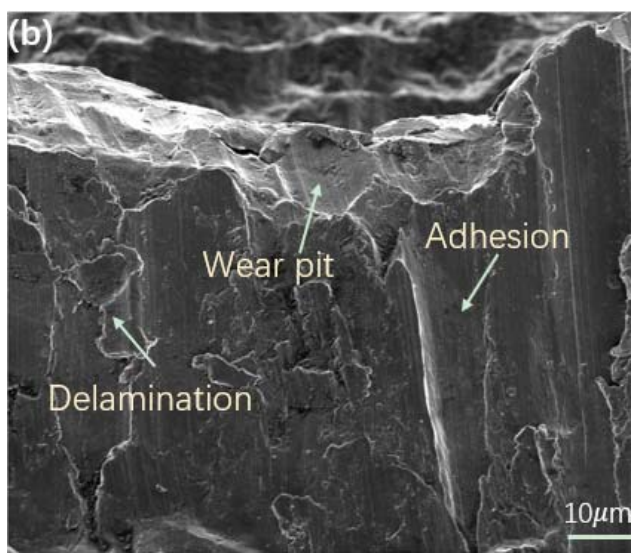



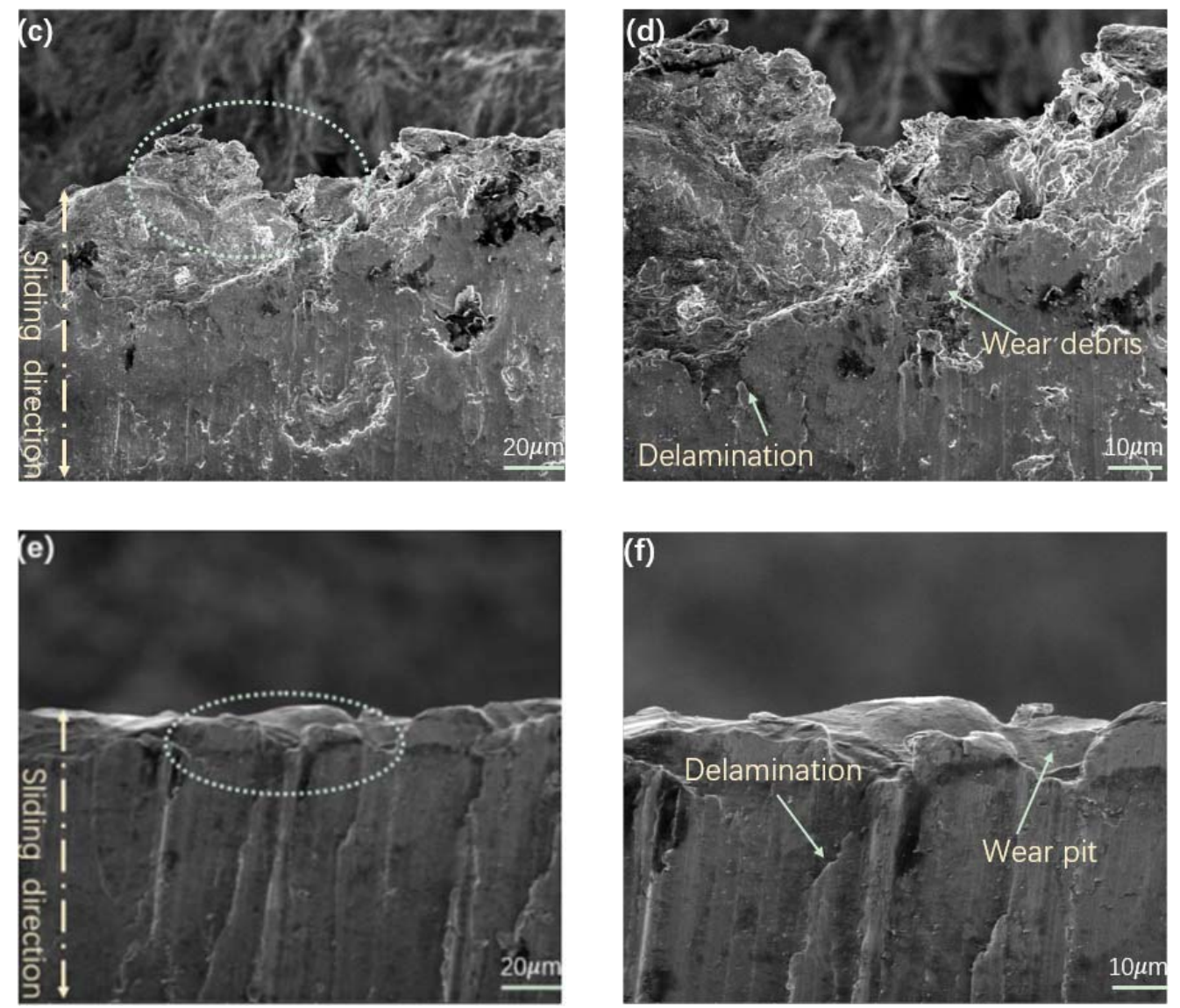

Fig. 11 SEM images of the typical wear morphologies of (a\&b)AsR specimen (c\&d)SP specimen and (e\&f)USRP specimen.

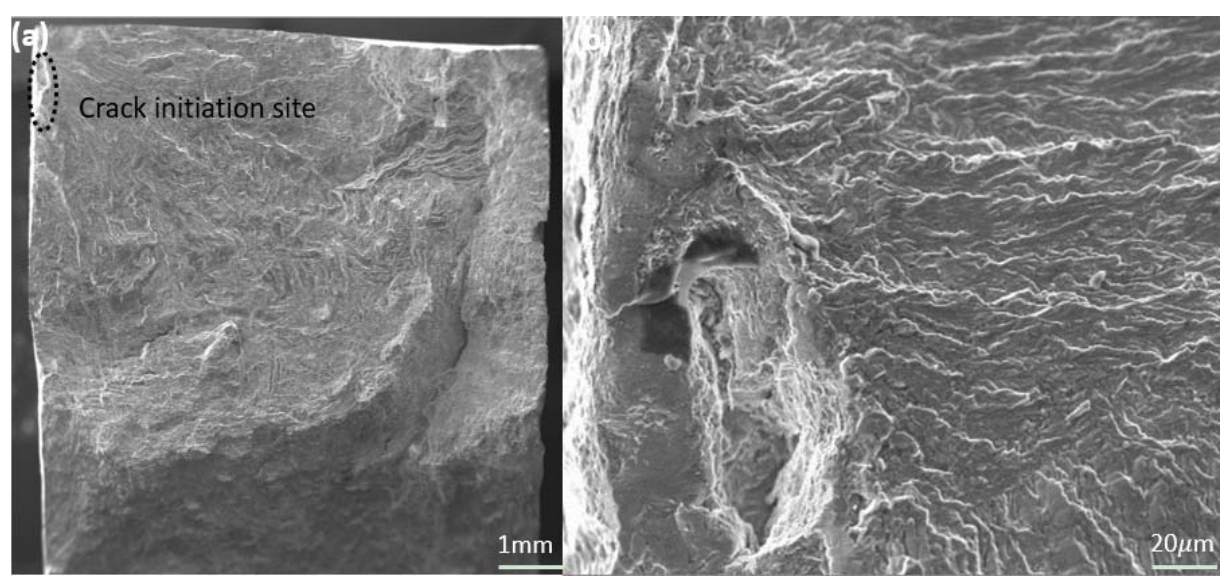



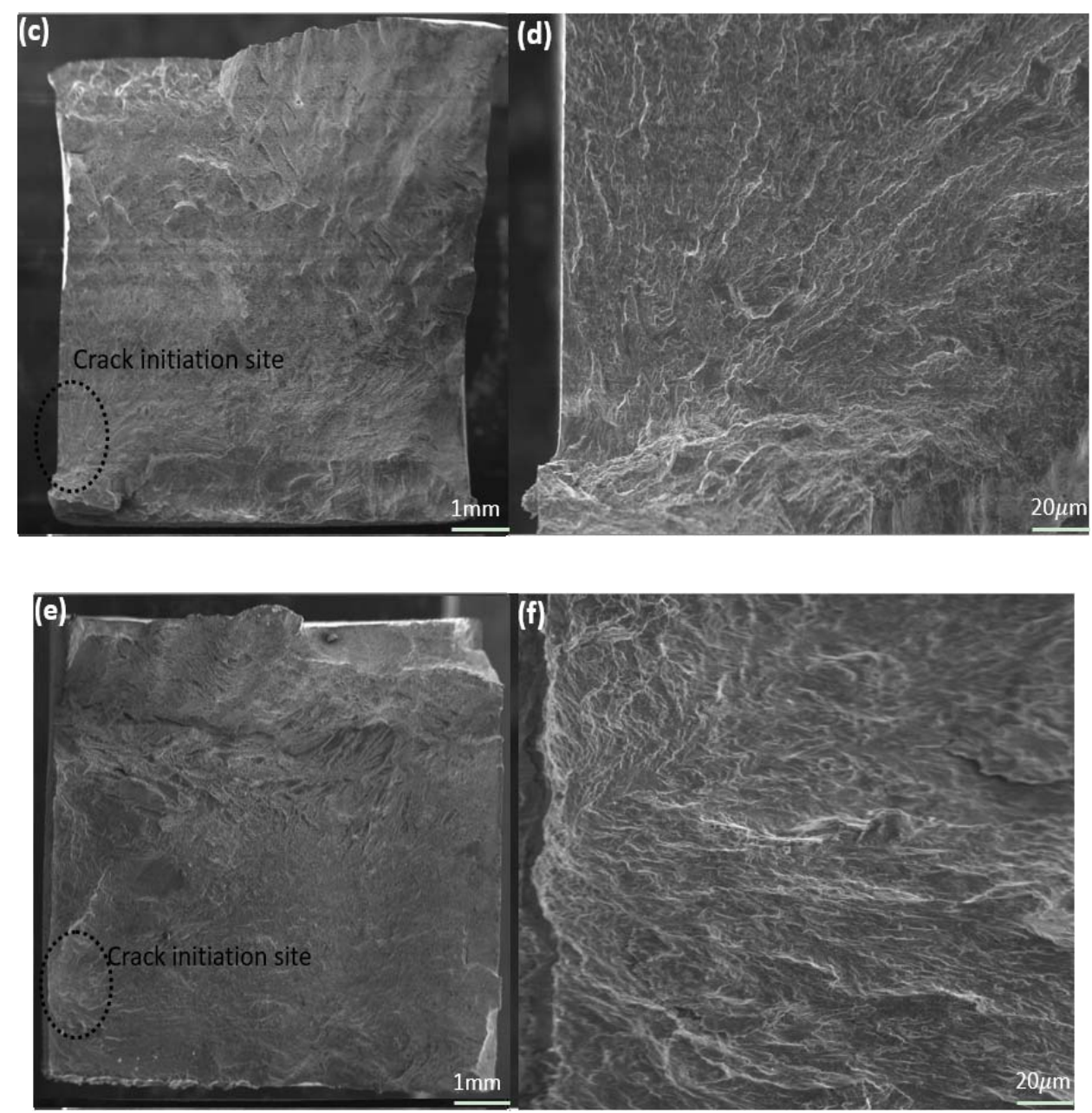

Fig. 12 SEM fracture surface morphologies of (a\&b)AsR specimen (c\&d)SP specimen and (e\&f)USRP specimen

\subsection{Fretting fatigue life}

Residual stress and surface roughness are considered to be the most critical factors affecting fretting fatigue life. The residual stress introduced by surface and sub-surface layers of the specimen after surface strengthening is compressive stress, which can effectively reduce the average stress caused by the applied load and reduce the stress ratio, thereby preventing the initiation of fatigue cracks and reducing the crack growth rate. Therefore, residual stress is often considered to be the average stress. The effect of surface roughness on fatigue is usually attributed to the stress concentration effect. Lower roughness helps the specimen avoid surface stress concentration during the fretting fatigue experiment and prevent crack initiation that caused by surface defects, especially for low-cycle fatigue experiment under high stress levels. This is mainly because the residual stress is prone to relaxation under high stress levels [27]. For the fretting fatigue damage with the coupling effect of fretting wear and fatigue damage, the importance of surface hardness can not be ignored, especially in the overall sliding state.According to the Archard wear equation, the wear volume is proportional to the surface hardness of the material. Therefore, the higher the surface hardness is, the stronger the wear resistance is and the longer the fretting fatigue life is.

The fretting fatigue life curves are shown in Fig. 13. The fretting fatigue life under three different test conditions are all decrease with the increase of stress level. Moreover, the lower the stress level, the more obvious the strengthening effect. Among two strengthening methods, USRP has a more significant effect on the improvement of fretting fatigue life, especially under the stress level of $600 \mathrm{Mpa}$. In the early stage of fretting fatigue crack growth, the residual compressive stress can significantly reduce the tensile stress at the crack tip [31]. Similar to clamping stress, compressive residual stress can also close fretting fatigue cracks at the early stage of fretting fatigue crack propagation [17]. At the same time, the surface roughness and surface microhardness of the samples have been greatly improved, which can improve the wear resistance and stress concentration of the samples. The coupling effect of the 
above three parameters greatly improves the fretting fatigue life.In the stress range of 600 650Mpa, SP does not significantly improve the fatigue life of Ti-6Al-4V. The research on the effect of SP on the fatigue strength of cast iron structure shows that higher residual compressive stress and nanocrystalline structure help to improve the fatigue strength, but the high roughness caused by SP will greatly weaken the above effect [32]. Generally speaking, parts with larger friction coefficients are more susceptible to fretting damage, especially titanium alloys that are more sensitive to fretting wear. In addition, some researchers[3335] proved that SP will change the surface morphology and increase the roughness of the material while introducing residual stress. The increase of roughness will cause some unfavorable results like surface stress concentration, microcracks, etc. In the study of the effect of different SP treatments on the fretting fatigue life of 7075-t7351 aluminum alloy, it is found that laser SP can increase the fatigue life of 7075-t7351 aluminum alloy at the early and late stages of crack propagation by 7 and 3 times respectively.However, SP can only increase by 2 to 3 times. The main reason is that the SP process can easily cause embrittlement and roughening of the material surface. In addition, in the process of SP, the surface of the material will form a region which is easy to promote the rapid propagation of cracks. These will greatly weaken the beneficial effect of residual compressive stress. The surface brittleness and roughness caused by SP can also aggravate the fretting wear of the material, which makes the surface of the material easy to fall off, delamination and even appear pits or microcracks. Moreover, under the action of high strain amplitude, the residual compressive stress will relax, which weakens the ability of residual compressive stress to resist crack initiation.

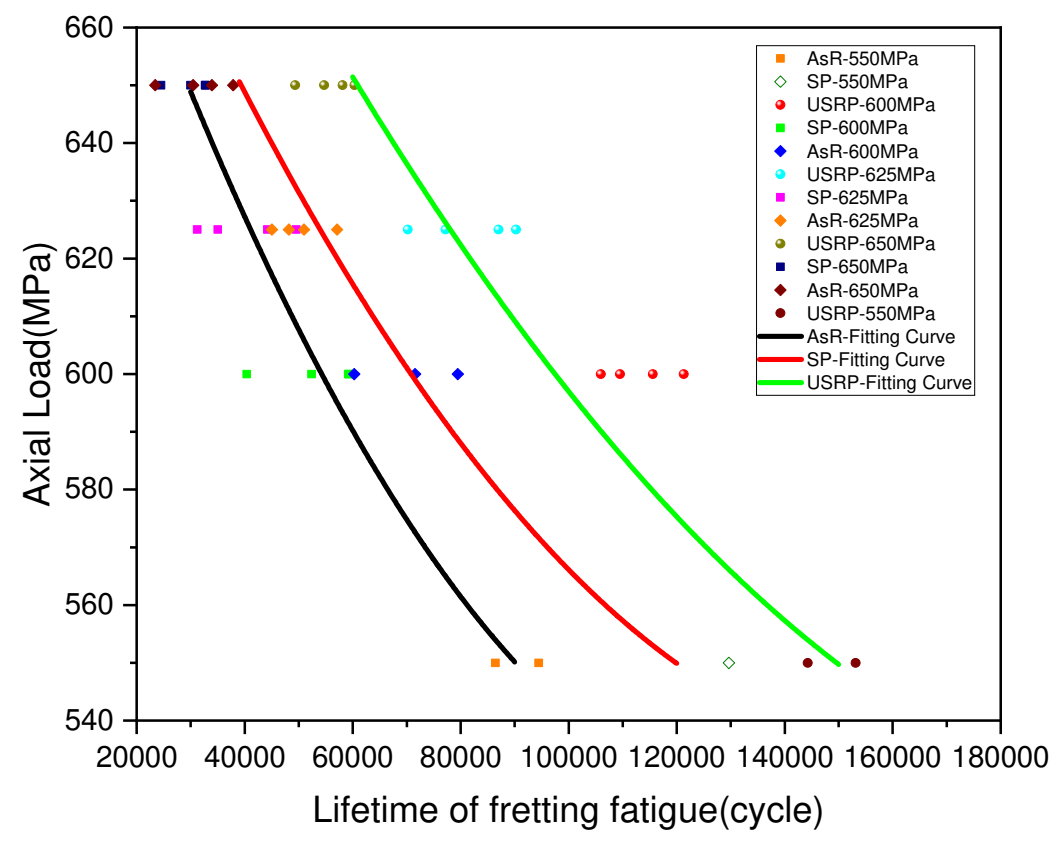

Fig. 13 Stress vs. number of fertting fatigue cycles (S-N curves) of the AsR、SP and USRP specimens. After the SP, the fatigue strength $(550 \mathrm{MPa})$ are shown as open symbols, which is a predicted data.

\section{Conclusions}

In the present study, an experimental investigation on the fretting fatigue behavior of Ti-6Al-4V plate specimens after different was conducted using a self-designed test system. In this paper, the fretting fatigue behavior of Ti6Al-4V plate specimens after surface strengthening treatment was studied by using a self-designed test system. The test device is equipped with clamping system, which can ensure the accuracy and stability of long-time test, and can easily change various contact geometry. The micromorphology characteristics of the specimen wear scar and fracture surface were analyzed by SEM. The surface hardness and residual stresses of the material after SP and USRP process were tested by vickers indenter and X-ray diffraction residual stress analyzer. The comparison analysis for the wear and fracture phenomena of the AsR, SP and USRP specimens were performed and the effect of two surface treatments had on the fretting wear behavior of Ti-6Al-4V was evaluated. The main conclusions are as follows:

(1)The surface hardness of specimens strengthened by SP and USRP increased by $38.4 \%$ and $46.2 \%$, respectively. The surface roughness of USRP specimens are reduced by $34.1 \%$.

(2)During the long-term fretting process, the material loss and no crack nucleation can be observed as fretting 
damage for this gross sliding cases, which is due to the domination of the mechanisms of adhesion and surface delamination.

(3)Compared with SP specimens, USRP specimens have a better improvement in the fretting fatigue lifetime, which means lower surface roughness can effectively mitigate the undesired effects that fretting wear has on specimens.

(4)Both SP and USRP specimens show better fretting fatigue resistance, owing to the beneficial effects of the enhanced hardness, the strain-hardening layer and the compressive residual stress.

\section{Declaration}

\section{Acknowledgements}

The authors sincerely thanks to Associate Professor Peng Zhao and Xiao Li from East China University of science and technology for their critical discussion during the experiment.

\section{Funding}

Supported by National Key Research and Development Project (Grant No.2018YFC1902400) and Natural Science Foundation of Shanghai (Grant No. 20ZR1415300).

\section{Availability of data and materials}

The datasets supporting the conclusions of this article are included within the article.

\section{Authors' contributions}

The author' contributions are as follows: Ning Wang was in charge of the whole trial; Jinlong Zhu wrote the manuscript; Bai Liu and Jiamin Zhang assisted with sampling and laboratory analyses. Xiancheng Zhang and Shantung $\mathrm{Tu}$ were responsible for providing idea and revising the manuscript.

\section{Competing interests}

The authors declare no competing financial interests.

\section{Consent for publication}

Not applicable

\section{Ethics approval and consent to participate}

Not applicable

\section{References}

[1] M J He.Fretting fatigue of mechanical components. Beijing: National Defense Industry Press, 1994. (in Chinese) [2] M Ciavarella,G Demelio. A review of analytical aspects of fretting fatigue, with extension to damage parameters, and application to dovetail joints[J]. International Journal of Solids and Structures, 2001, 38(10-13): 1791-1811.

[3] J K Duan,X Y Yang,L W Dong,et al.Research on Fracture of Compressor Blade Dovetail from Fretting Wear. Gas Turbine Experiment and Research,2009,22(03):28-32. [4] C Ruiz,K C Chen. Life assessment of dovetail joints between blades and discs in aero-engines. Mechanical Engineering Publications, 1986: 187-194.

[5] R Rajasekaran,D Nowell. Fretting fatigue in dovetail blade roots: Experiment and analysis. Tribology international, 2006, 39(10): 1277-1285.

[6] G Chen,J Yan,T Tian, et al. Effect of wet shot peening on Ti-6Al-4V alloy treated by ceramic beads. Transactions of Nonferrous Metals Society of China, 2014, 24(3): 690696.

[7]S Bagherifard,S Slawik,I Fernández-Pariente, et al. Nanoscale surface modification of AISI 316L stainless steel by severe shot peening. Materials \& Design, 2016, 102: 6877.

[8] J Z Lu,L J Wu,G F Sun, et al. Microstructural response and grain refinement mechanism of commercially pure titanium subjected to multiple laser shock peening impacts. Acta Materialia, 2017, 127: 252-266.

[9] S Srinivasan,D B Garcia, M C Gean, et al. Fretting fatigue of laser shock peened Ti-6Al-4V. Tribology International, 2009, 42(9): 1324-1329.

[10]P J Golden,M J Shepard. Life prediction of fretting fatigue with advanced surface treatments. Materials science and engineering: $a, 2007,468$ : 15-22.

[11] Y Zhang,S Descartes,P Vo, et al. Cold-sprayed CuMoS 2 and its fretting wear behavior. Journal of thermal spray technology, 2016, 25(3): 473-482.

[12] Q Yang, W Zhou, X Zheng, et al. Investigation of shot peening combined with plasma-sprayed CuNiIn coating on the fretting fatigue behavior of Ti-6Al-4V dovetail joint specimens. Surface and Coatings Technology, 2019, 358: 833-842.

[13] Tang C, Liu D, Tang B, et al. Influence of plasma molybdenizing and shot-peening on fretting damage behavior of titanium alloy. Applied Surface Science, 2016, 390: 946-958.

[14] Z R Zhou,L Vincent.Fretting wear. Beijing: Science Press:2002. 
[15] K Li,X Fu, R Li, et al. Fretting fatigue characteristic of Ti-6Al-4V strengthened by wet peening. International Journal of Fatigue, 2016, 85: 65-69.

[16] J Liu,X Zhang,Z Cui, et al. Effects of ultrasonic surface rolling processing and plasma nitriding on the fretting wear behavior of Inconel 690TT. Surface and Coatings Technology, 2020, 402: 126312.

[17] D Liu,B Tang,X Zhu, et al. Improvement of the fretting fatigue and fretting wear of Ti6Al4V by duplex surface modification. Surface and coatings Technology, 1999, 116: 234-238.

[18] C Liu,D Liu,X Zhang, et al. Fretting fatigue characteristics of Ti-6Al-4V alloy with a gradient nanostructured surface layer induced by ultrasonic surface rolling process. International Journal of Fatigue, 2019, 125: 249-260.

[19] L X Lu,J Sun,L Li, et al. Study on surface characteristics of 7050-T7451 aluminum alloy by ultrasonic surface rolling process. The International Journal of Advanced Manufacturing Technology, 2016, 87(9-12): 2533-2539.

[20]Y S Zeng.Application of Shot Peening Technology in the Development of Integral Panels of Civil Aircraft.Aeronautical Manufacturing Technology.2008,(1):54-55.

[21] I F Pariente,M Guagliano. About the role of residualstresses and surface work hardening on fatigue $\Delta \mathrm{K}$ th of a nitrided and shot peened low-alloy steel. Surface and Coatings Technology, 2008, 202(13): 3072-3080.

[22] J Huang.Effect of low parameters ultrasound-aided deep rolling on the high cycle fatigue performance of Ti6Al-4V alloy.Shanghai.East China university of science and technology.2019 (in Chinese)

[23] W Ting,W Dongpo,L Gang, et al. Investigations on the nanocrystallization of $40 \mathrm{Cr}$ using ultrasonic surface rolling processing. Applied Surface Science, 2008, 255(5): 18241829.

[24] Q Zhang,Z Hu,W Su, et al. Microstructure and surface properties of 17-4PH stainless steel by ultrasonic surface rolling technology. Surface and Coatings Technology, 2017, 321: 64-73.

[25] K Dalaei,B Karlsson,L E Svensson. Stability of shot peening induced residual stresses and their influence on fatigue lifetime. Materials Science and Engineering: A,
2011, 528(3): 1008-1015.

[26] $H$ Wohlfahrt $H$. Shot peening and residual stresses.Residual stress and stress relaxation. Springer, Boston, MA, 1982: 71-92.

[27] Y K Gao, X R Wu,L M Lei. Influence of laser peening and shot peening on fatigue properties of FGH97 superalloy. RARE METAL MATERIALS AND ENGINEERIN. 2016,45(05):1230-1234.

[28] A L M Tobi,J Ding,G Bandak, et al. A study on the interaction between fretting wear and cyclic plasticity for Ti-6Al-4V. Wear, 2009, 267(1-4): 270-282.

[29] X L Liu,Z Zhang,C H Tao.Fatigue fractegraphy quantitative analysis. Beijing: National Defense Industry Press,2010. (in Chinese)

[30] Q Yang, W Zhou,Z Niu, et al. Effect of different surface asperities and surface hardness induced by shot-peening on the fretting wear behavior of Ti-6Al-4V. Surface and Coatings Technology, 2018, 349: 1098-1106.

[31] Waterhouse R B, Trowsdale A J. Residual stress and surface roughness in fretting fatigue. Journal of Physics D: Applied Physics, 1992, 25(1A): A236.

[32] Z Y Li,X L Liu,G Q Wu, et al. Observation of fretting fatigue cracks of Ti6Al4V titanium alloy. Materials Science and Engineering: A, 2017, 707: 51-57.

[33] Bagherifard S, Fernandez-Pariente I, Ghelichi R, et al. Effect of severe shot peening on microstructure and fatigue strength of cast iron. International Journal of Fatigue, 2014, 65: 64-70.

[34] L B Zheng. The effect of shot peening residual stress and roughness on fatigue life of 2024 aluminum alloy by simulation and experimental study. Shangdong.Shangdong University,2017. (in Chinese)

[35] Montross C S, Wei T, Ye L, et al. Laser shock processing and its effects on microstructure and properties of metal alloys: a review. International journal of fatigue, 2002, 24(10): 1021-1036. 


\section{Figures}

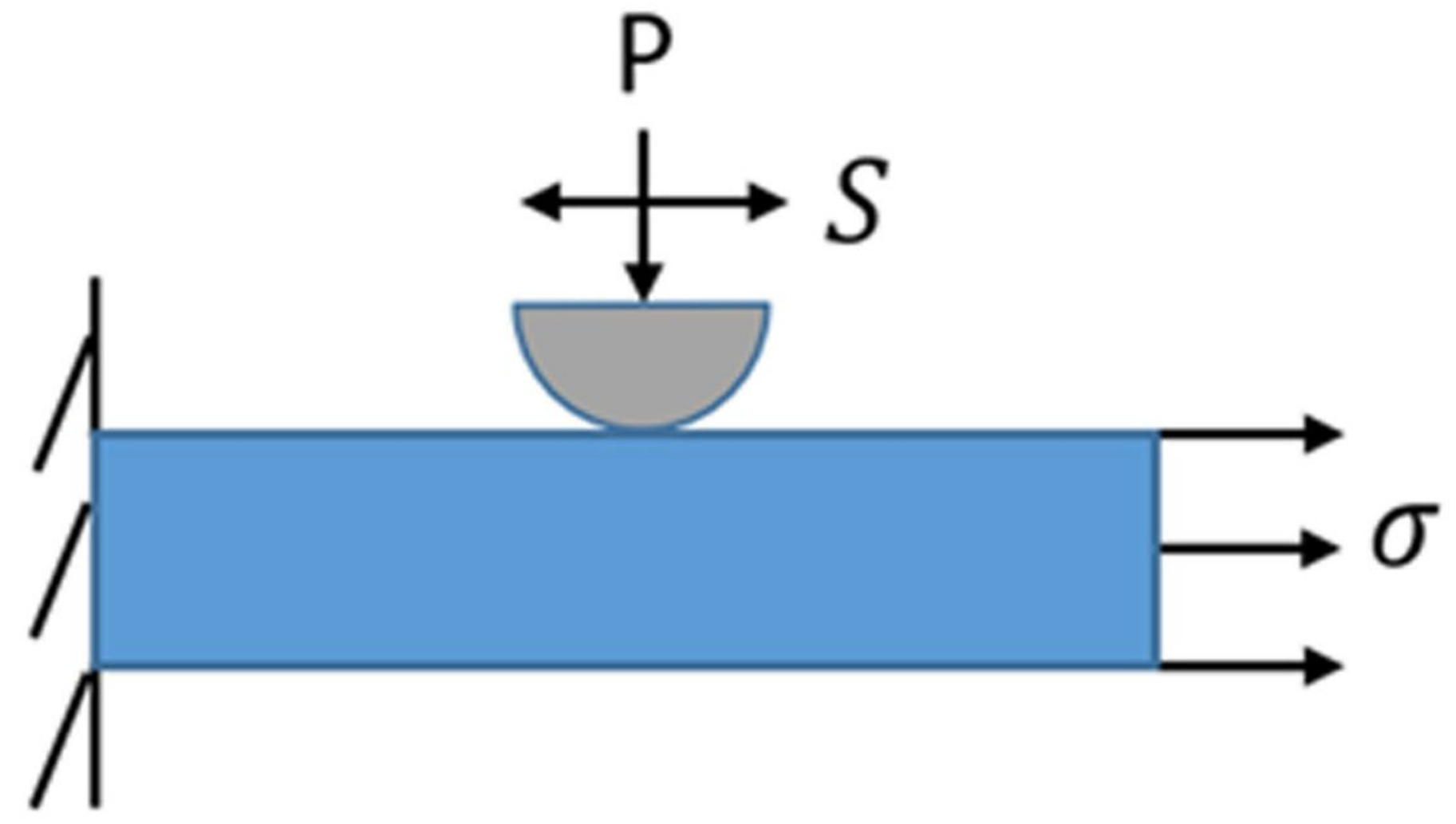

Figure 1

Schematics of the fretting fatigue.
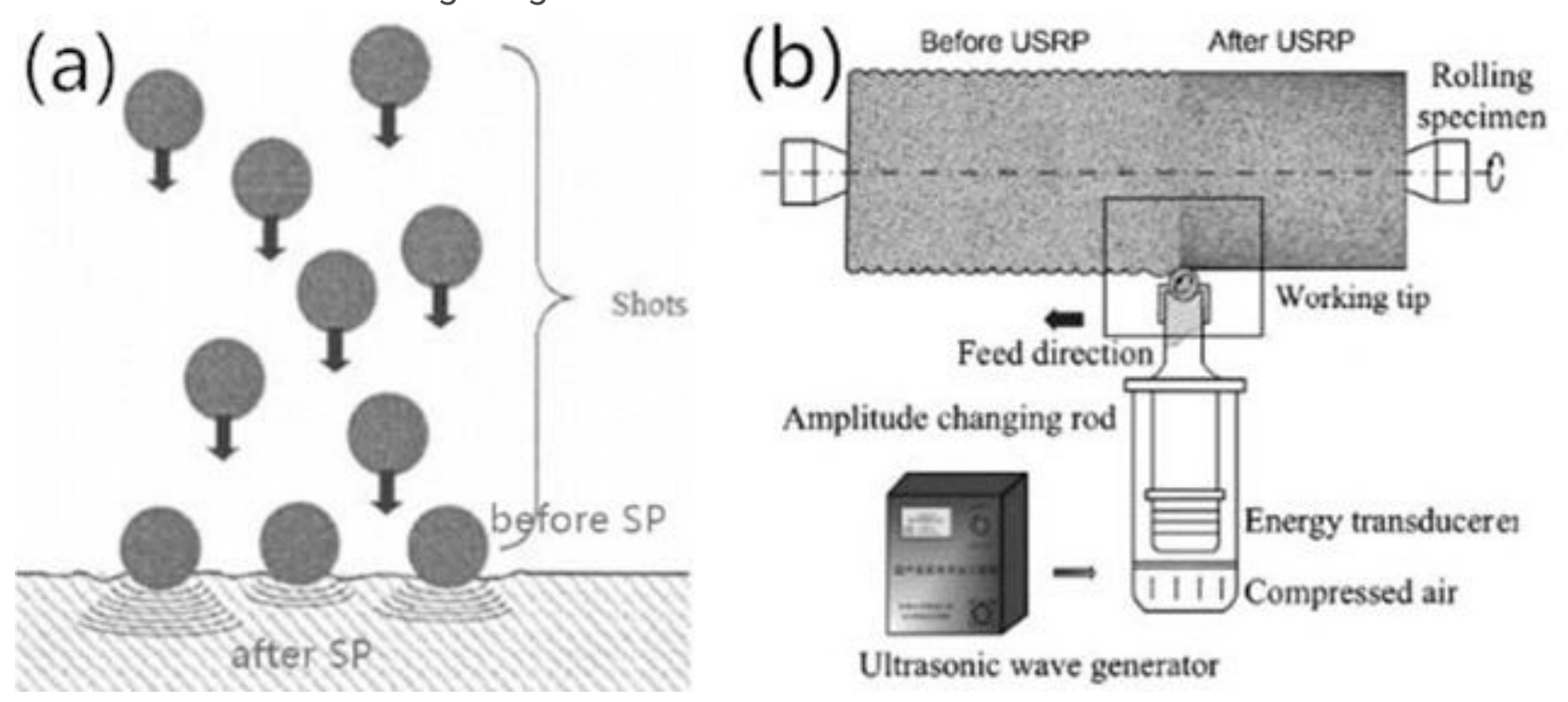

Figure 2

Schematics of different surface strengthening processes: (a) SP [22] (b)USRP [23]. 


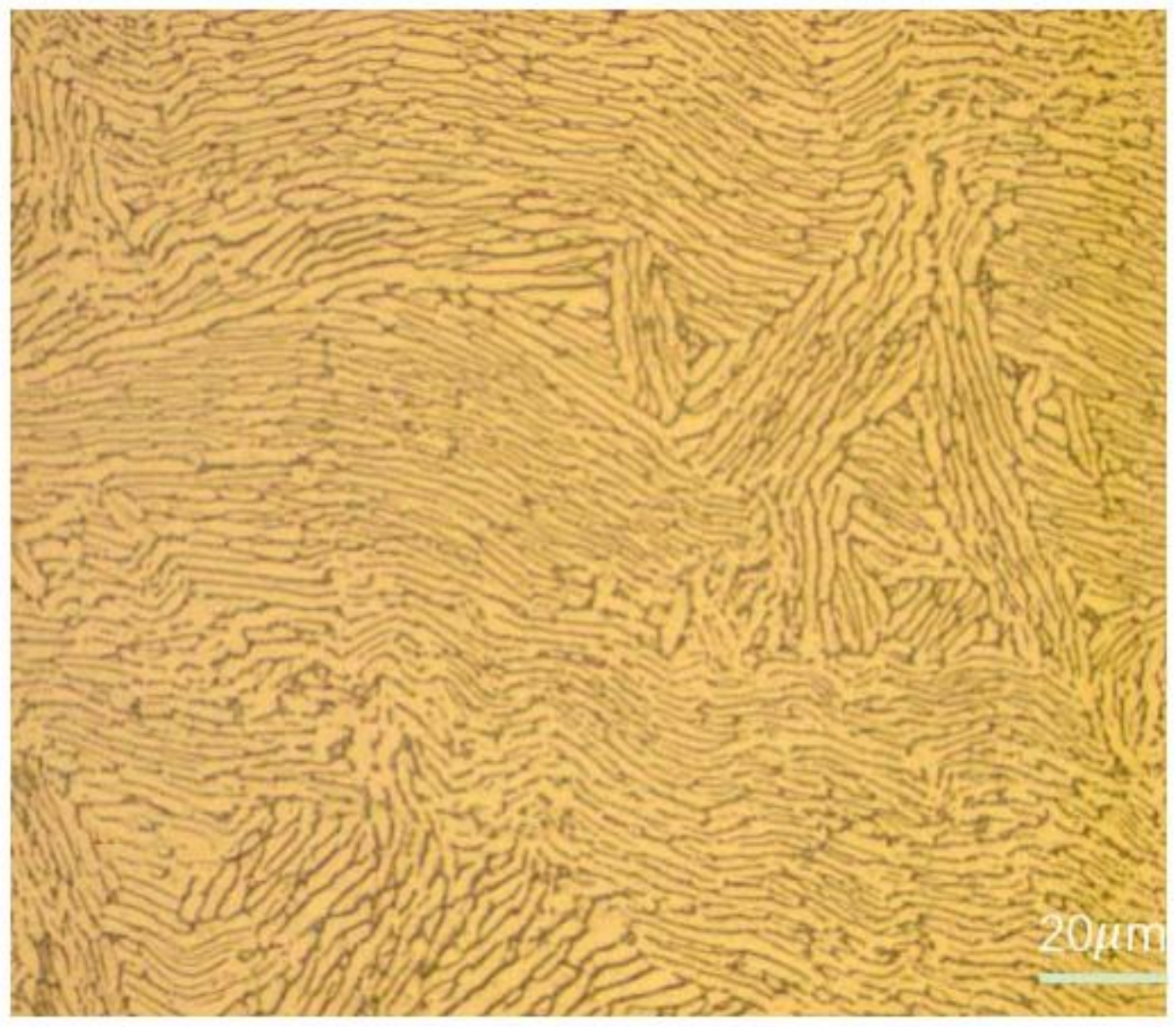

\section{Figure 3}

The microstrcture image of specimen.

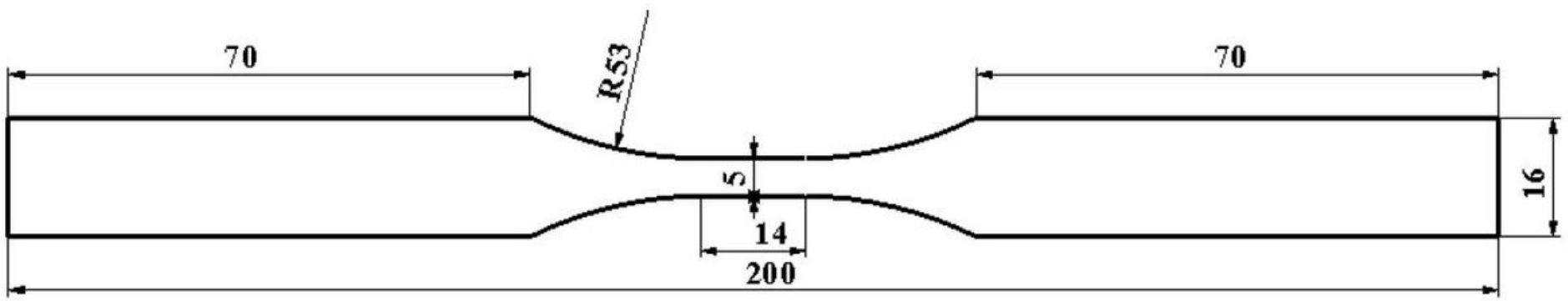

Figure 4

Geometric details of the specimen. (units:mm).

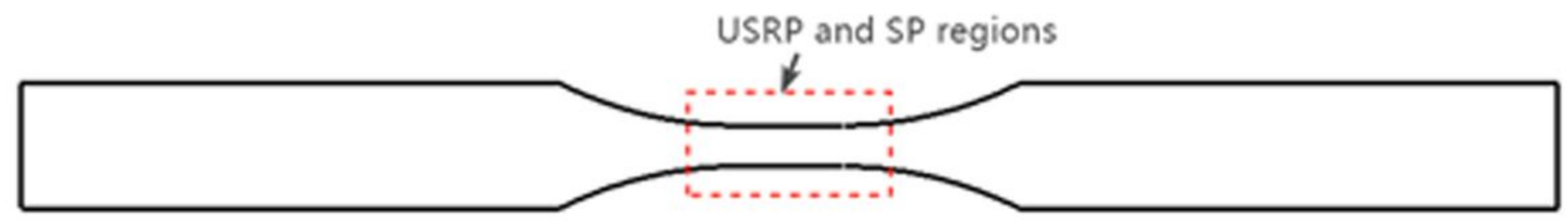


Figure 5

Schematics of USRP and SP treatment regions.

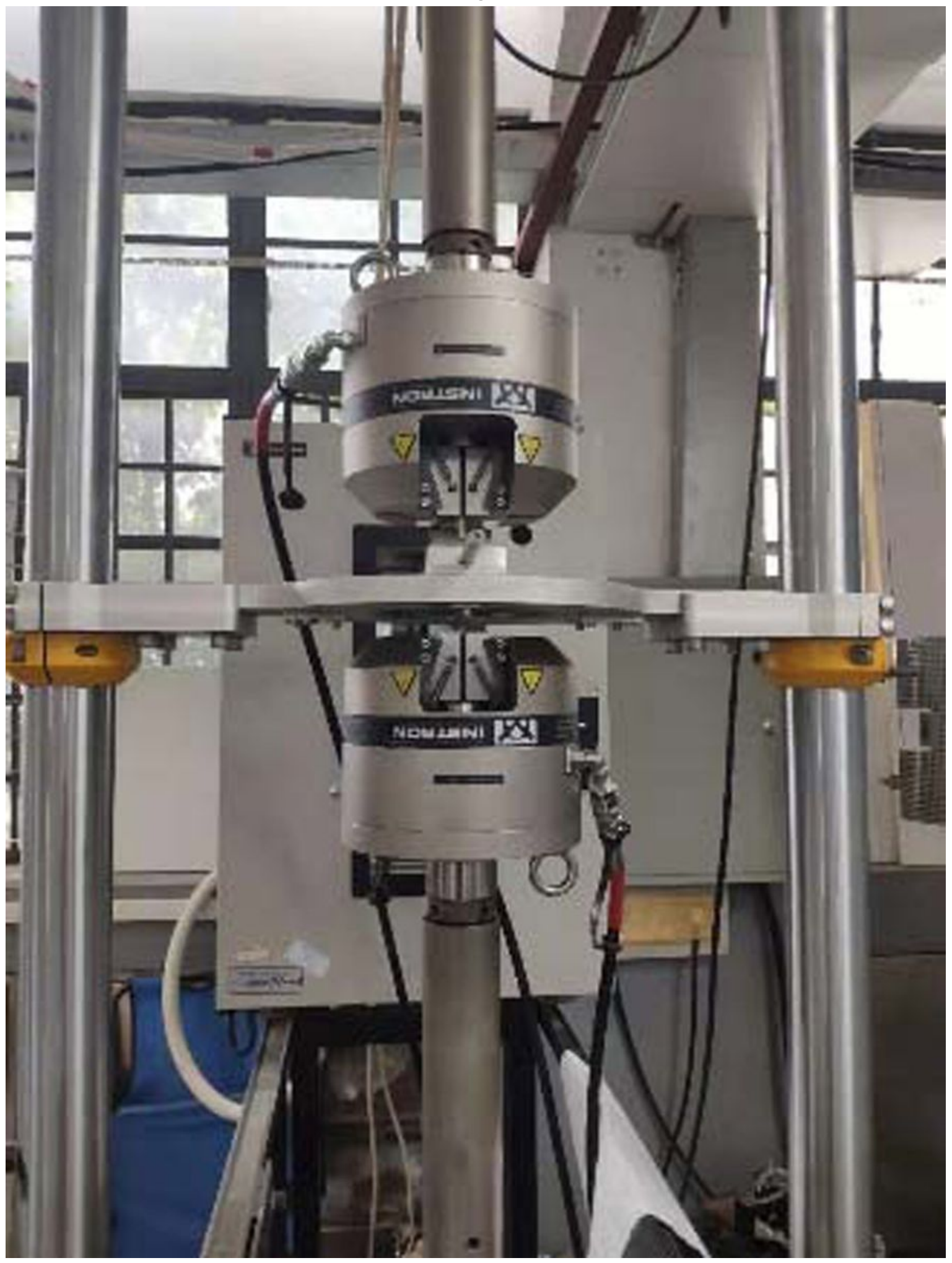

Figure 6

The fretting fatigue experiment machine. 


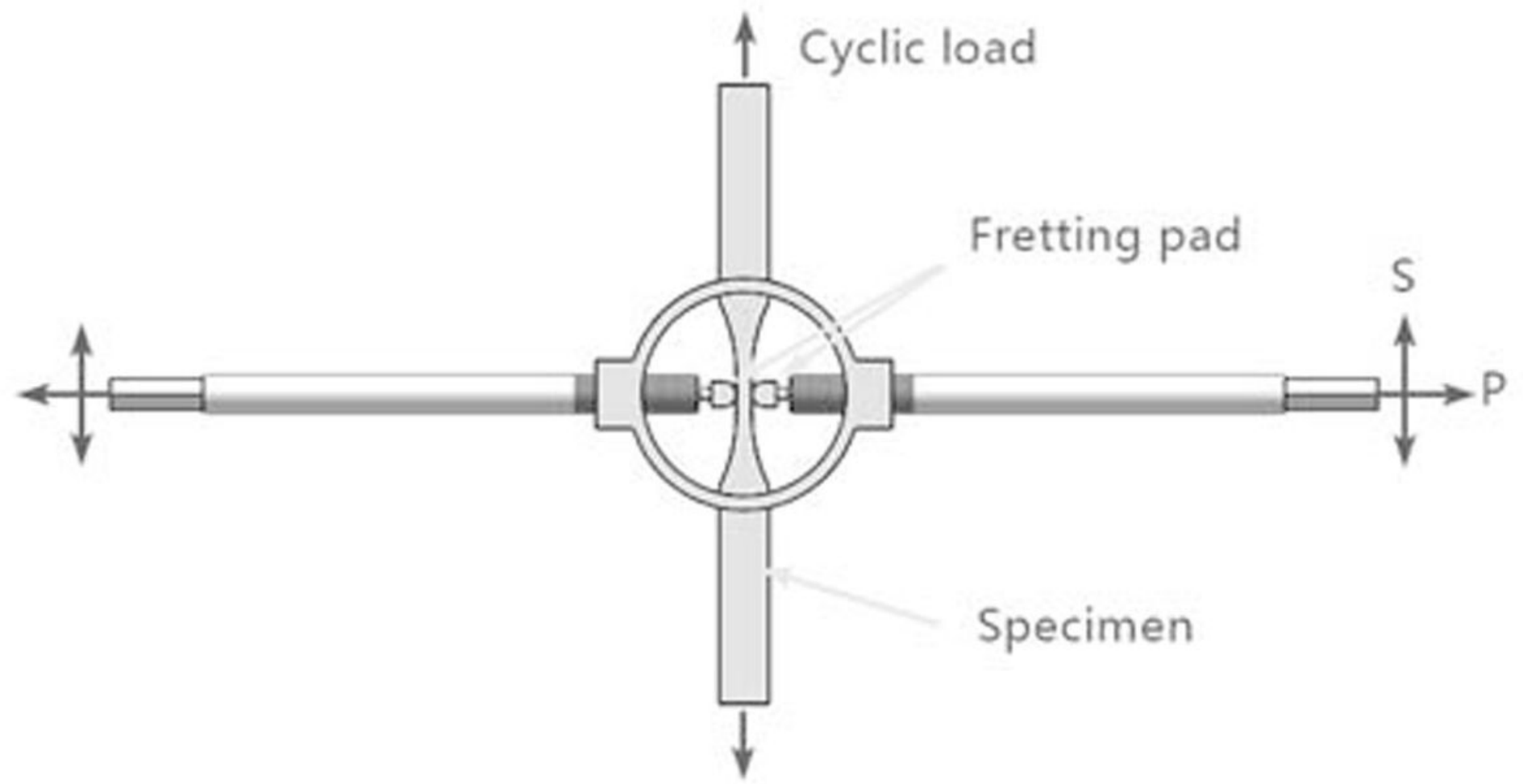

Figure 7

Schematic of fretting wear arrangement. 

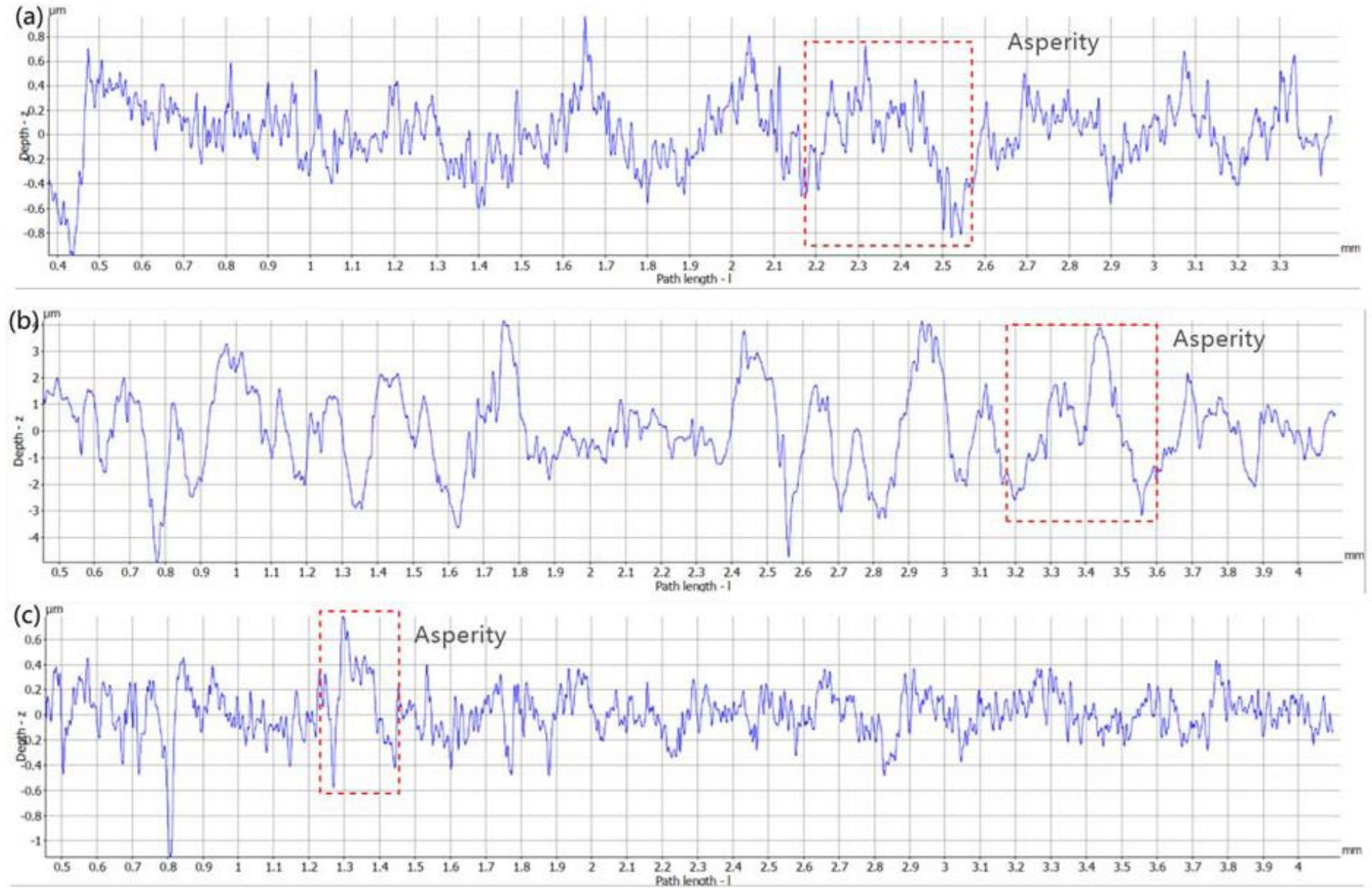

\section{Figure 8}

The surface roughness of the (a)AsR,(b)SP and (c)USRP specimens

\section{Image not available with this version}

\section{Figure 9}

The Microhardness distribution of the AsR,SP and USRP specimens 


\section{Image not available with this version}

Figure 10

Distribution of compressive residual stress of the SP and USRP specimens 

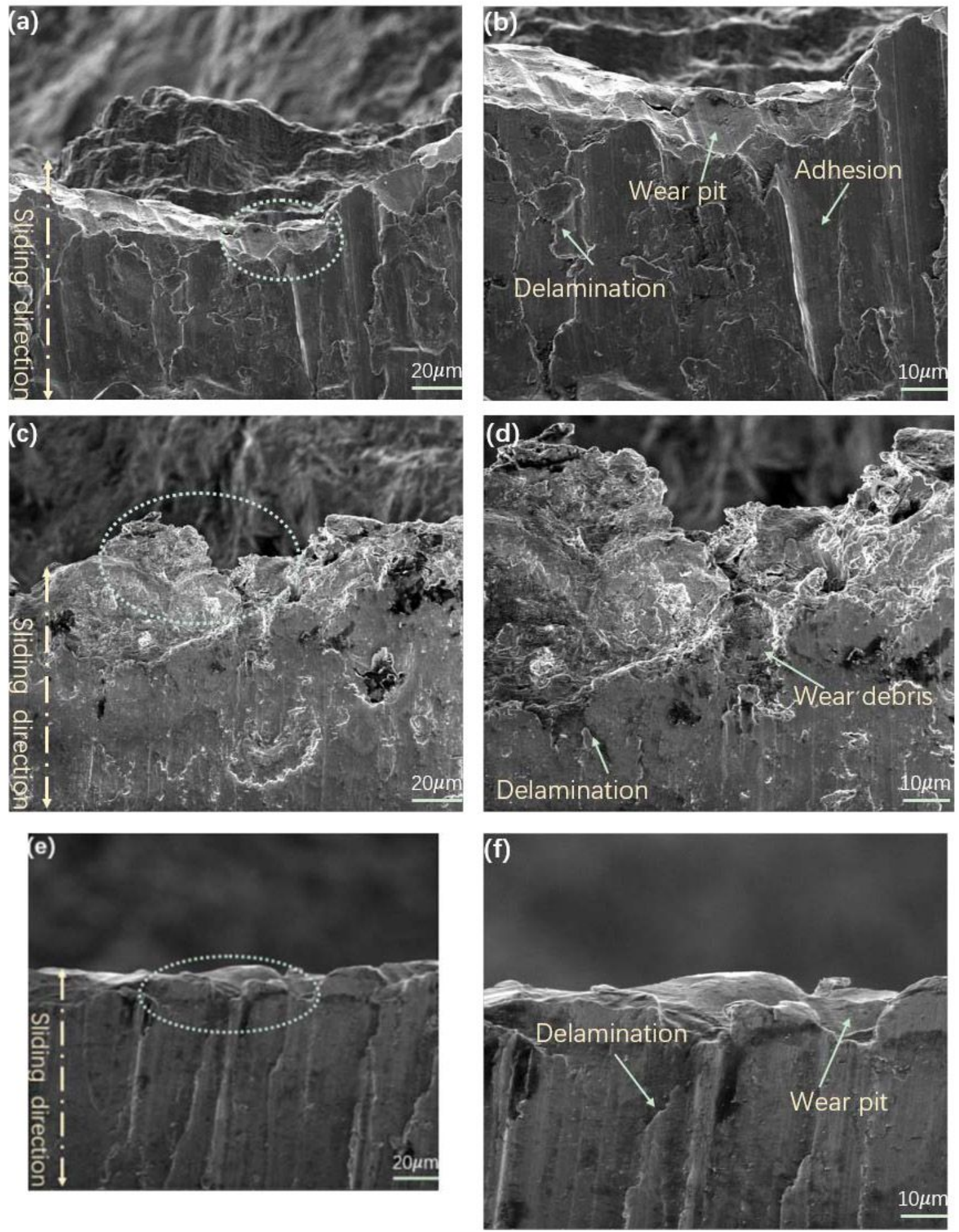

Figure 11

SEM images of the typical wear morphologies of (a\&b)AsR specimen (c\&d)SP specimen and (e\&f)USRP specimen. 

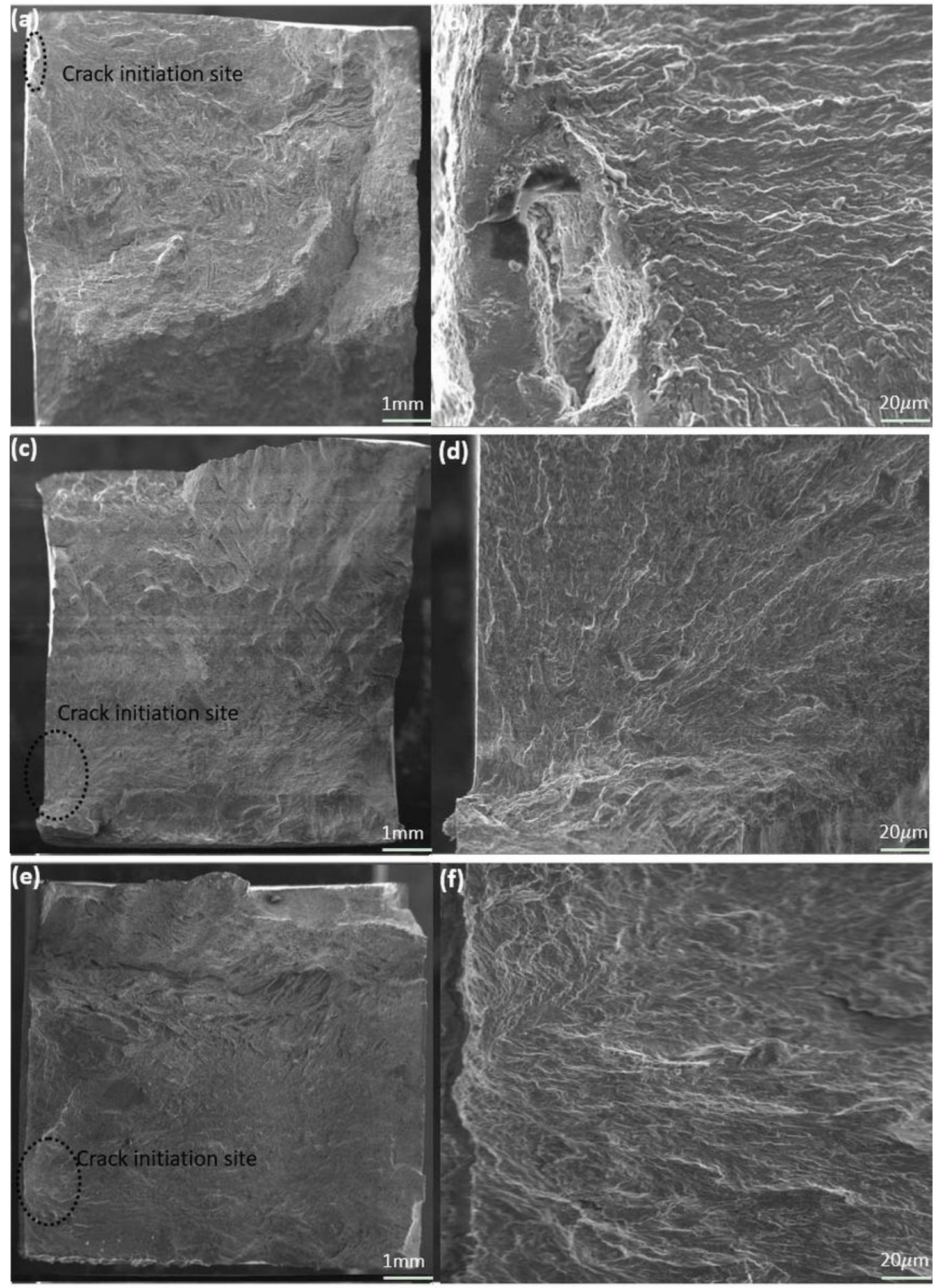

Figure 12

SEM fracture surface morphologies of (a\&b)AsR specimen (c\&d)SP specimen and (e\&f)USRP specimen 


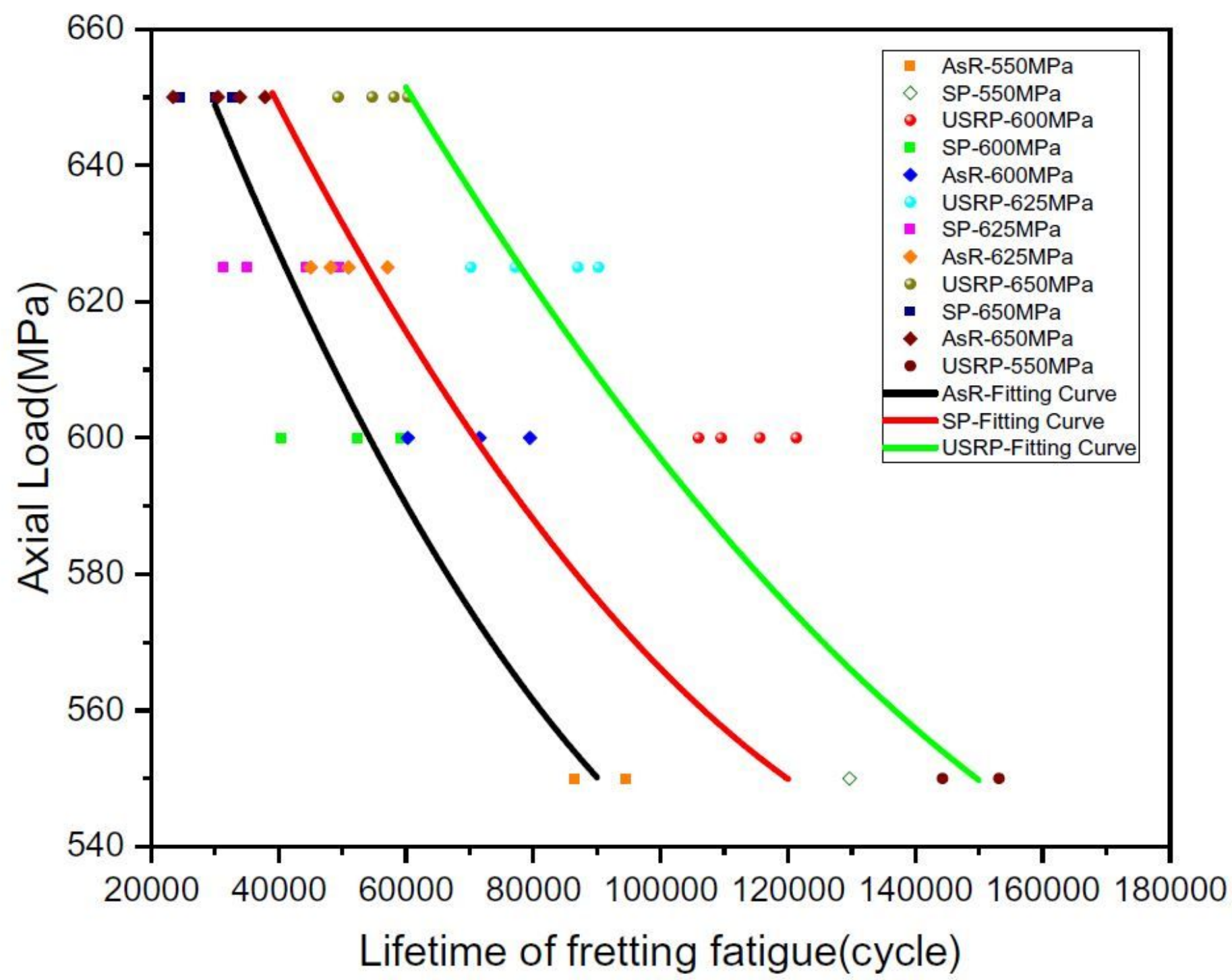

Figure 13

Stress vs. number of fertting fatigue cycles (S-N curves) of the AsR $\square$ SP and USRP specimens. After the $\mathrm{SP}$, the fatigue strength $(550 \mathrm{MPa})$ are shown as open symbols,which is a predicted data. 